I have myself suffered four attacks of typical migraine in the last nine years. The first attack in November 1963 occurred quite spontaneously, but subsequent attacks in November 1964, November 1965, and November 1968, all occurred while playing rugby football.

On each occasion the attacks were preceded by a blow to the face with hyperextension of the neck while making a tackle. Each attack started a few minutes after injury with a feeling of light-headedness, followed after about 15 minutes by homonymous hemianopia with fortification spectra, and tingling of the hand, side of the face, and tongue. Tiredness and nausea followed about two hours later lasting several hours.

After the second attack, clinical examination by a neurologist proved negative, and no other investigations have been performed. I have not heard of any similar cases arising from playing rugby although the unexpectedness of the trauma in rugby might make its occurrence more likely.-I am, etc.,

Canniesburn Hospital,

A. M. MORRIS Glasgow

\section{Aetiology of Varicosity}

SIR,-I was most interested to read $\mathrm{Mr}$. D. P. Burkitt's paper (3 June, p. 556) on the relationship between varicose veins and lowresidue diet. Some support for his hypothesis comes from J. H. S. Pettit ${ }^{1}$ writing from Shiraz in Iran. Surveying the incidence of different dermatoses encountered in Iran he drew attention to the extraordinary absence of gravitational ulceration of the leg there. $\mathrm{He}$ did not observe a single case among 9,000 Iranian patients examined. Since postpartum infection and thrombosis are at least as common in Iranian women as in British he suggested that other causes of such ulceration should be sought. It is interesting to note that the basic food of the Iranian people consists of bread prepared from whole wheat or barley except in the Caspian provinces, where rice is constantly employed as a substitute. $^{2}$

It would be difficult to imagine a dermatological clinic in Britain without its fair share of gravitational ulcers. Mr. Burkitt's suggestion gives a rational explanation for the difference.-I am, etc.,

W. A. D. GRIFFIthS St. John's Hospital for Diseases of the Skin,
London W.C.2

1 Petit, J. H. S., British Fournal of Dermatology, $1962,74,149$. III III, p. 183, Philadelphia, Lippincott, 1954 .

\section{Going Abroad}

SIR,-Your leading article (10 June, p. 604) and Dr. H. A. K. Rowland (p. 639) again drew attention to the increased prevalence of malaria in Britain, and rightly stress that doctors should cultivate a high degree of suspicion to improve the speed of diagnosis and treatment, thus, we hope, lowering the mortality (circa $10 \%$ ).

But malaria is a preventable disease. If travellers take adequate prophylaxis correctly they are unlikely to contract the disease. A helpful regimen is mentioned in your pages. But in many doctors' surgeries and clinics hangs a notice stating "Do not ask your doctor to supply you with drugs for use while you are abroad. The N.H.S. does not cover you, etc., etc." So the travellers do not.

Are we or are we not tryng to practise preventive medicine? -I am, etc.,

Helen B. Hannah

Southampton General Hospital,

Southampton Genera

SIR,-Dr. H. A. K. Rowlands (10 June, p. 639) commends the preparation Enterovioform for the prevention and treatment of diarrhoea, saying that it is "very unlikely to do harm."

This statement is incompatible with the evidence of an association between Enterovioform and the rare disease subacute myelo optic neuropathy (see B.M.f., 18 May 1971 , p. 291). Diarrhoea being a disorder which in healthy individuals is self limiting it surely is inadvisable to use a drug which can have such disastrous effects. It can be argued that Enterovioform should be withdrawn. Certainly it should not be used prophylactically.-I am, etc.,

Lincoln

W. Patrick Roe

\section{Benign Breast Swelling}

SIR,-May I be allowed to offer a third opinion on the case discussed by Dr. Roger Meyrick and Mr. Ivo Smith (3 June, p. 585). This lady aged 29 was complaining of tenderness and pain in her breasts during the premenstrual week, associated with generalized lumpiness. This condition, to which Sir Hedley Atkins has given the name of fibroadenosis, is benign and therefore should not be operated on and indeed could be cured surgically only by means of complete bilateral mastectomy. It is thought to be an expression of abnormal oestrogen activity and is usually completely relieved by administration of one of the oral progestogens in 10 or $15 \mathrm{mg}$ doses during the postovulatory phase of the cycle-say from the 15th to 25th day. Diuretics also help in some cases, presumably by lessening the degree of cyst formation which is the cause of the pain.-I am, etc.,

Chelsea Hospital for Women,
London S.W.3

P. M. F. BISHOP

\section{Monitoring of Carbon Dioxide in Anaesthesia}

SIR,-In most instances the concentration of $\mathrm{CO}_{2}$ in alveolar air is closely related to the $\mathrm{PCO}_{2}$ and as such suggests a convenient method of monitoring the $\mathrm{PCO}_{2}$ during anaesthesia or intensive care. This is a preliminary account of an instrument which might be useful in this application using the principle of conductimetric analysis of aerated deicnized water.

Deionized water is virtually a semiconductor and its resistance alters consider-

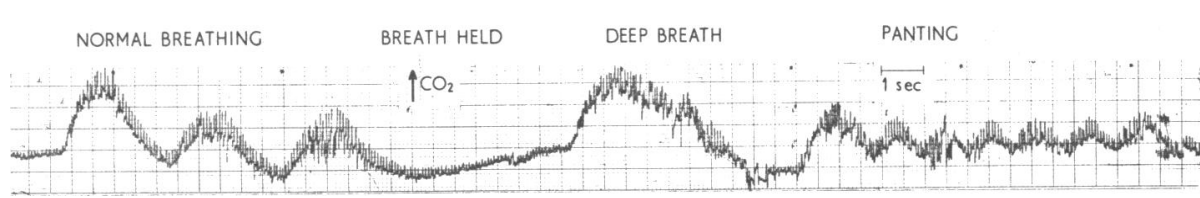

ably on the addition of any molecule which will dissociate to give a soluble ion. The hydrogen ion being the most mobile is the most significant ion in this respect, and carbon dioxide at low concentrations in water dissociates almost completely so that conductimetric analysis is an effective means of analysis. Further advantages are that the vast majority of volatile or gaseous anaesthetics do not give a soluble ion and many of the toxic contaminants do, so that the instrument may respond to toxic gases in a helpful way. The principle of the instrument is shown in the illustration. Air enters at the lower end of the air pump and as the bubbles ascend they carry up water past the electrodes and promote a circulation around and down through the mixed bed deionizing resin (Fig.).
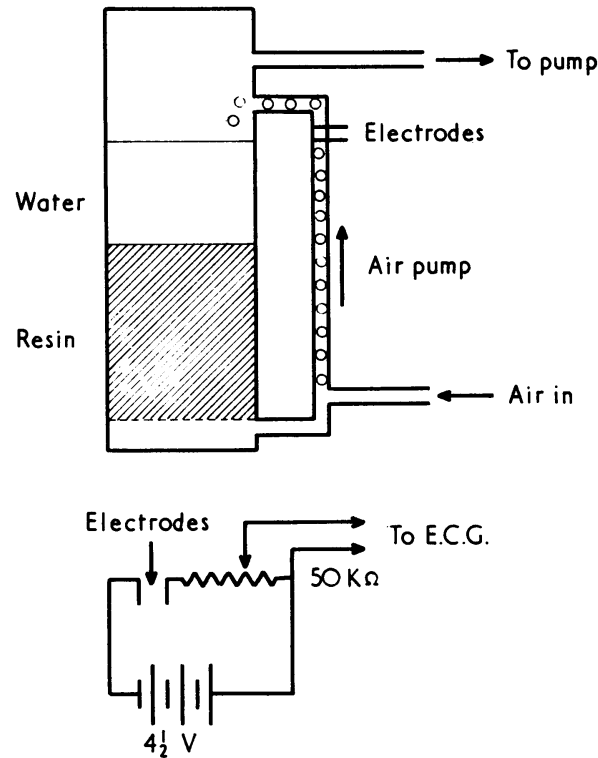

The electrodes consist of two fine stainless steel wires about $1 \mathrm{~mm}$ apart, and a Phillips electrocardiograph was used to record the resistance using the circuit shown. With an air flow of about $500 \mathrm{ml} / \mathrm{min}$ and an input tubing of narrow bone $(0.3 \mathrm{~mm})$ the time constant is sufficiently short to give a $\mathrm{CO}_{2}$ profile of respiration, the peak of the curve being related to the alveolar $\mathrm{CO}_{2}$ and hence presumably to the $\mathrm{PCO}_{2}$. As can be seen from the tracing there is considerable intereference from irregularities of bubble flow through the air pump. However, it is hoped that improvement in electrode construction will remedy this. In an improved form it is hoped that the instrument may have a useful application in anaesthesia and intensive care. $\overline{\mathbf{I}}$ am, etc.,

Marlow, Bucks

BRENNIG JAMES

\section{Intramuscular Injection and Coagulation Defects}

SIR.-The recent admission of two haemophiliacs for treatment following intramuscular injections prompts me to write muscular injections prompts me to write
about the need to avoid this type of therapy about the need to avoid this type 